
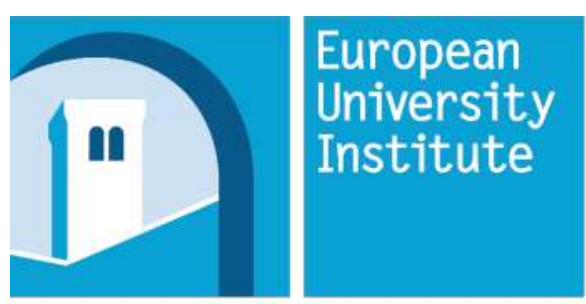

DEPARTMENT

OF

ECONOMICS
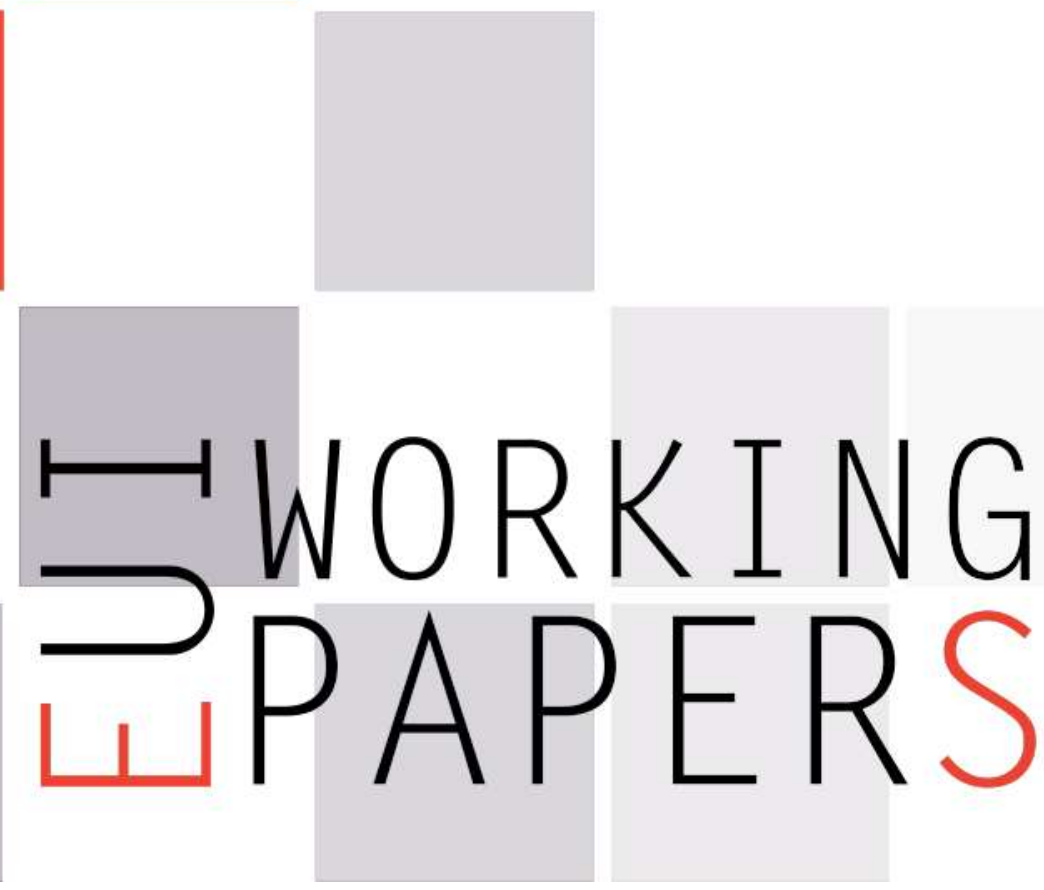

ECO 2016/03

Department of Economics

Optimal Inflation, Average Markups and Asymmetric Sticky Prices

Wojtek Paczos 

European University Institute

Department of Economics

Optimal Inflation, Average Markups and Asymmetric Sticky Prices

Wojtek Paczos

EUI Working Paper ECO 2016/03 
This text may be downloaded for personal research purposes only. Any additional reproduction for other purposes, whether in hard copy or electronically, requires the consent of the author(s), editor(s). If cited or quoted, reference should be made to the full name of the author(s), editor(s), the title, the working paper or other series, the year, and the publisher.

ISSN 1725-6704

(C) Wojtek Paczos, 2016

Printed in Italy

European University Institute

Badia Fiesolana

I - 50014 San Domenico di Fiesole (FI)

Italy

www.eui.eu

cadmus.eui.eu 


\title{
Optimal Inflation, Average Markups and Asymmetric STICKY PRICES*
}

\author{
Wojtek Paczos †a,b \\ ${ }^{a}$ Cardiff Business School, Cardiff University, Aberconway Building, Colum Drive, Cardiff CF10 3EU, United Kingdom \\ ${ }^{\mathrm{b}}$ Department of Economics, European University Institute, 50133 Firenze, Italy
}

November 2015

\begin{abstract}
In state-of-the-art New Keynesian model firms are monopolistically competitive and prices are sticky. However, the average markup resulting from the monopolistic competition is usually assumed away either by production subsidy or by the zero-inflation steady state. Also, in models of an open economy the same level of price stickiness is assumed for both countries. In this paper I study the optimal rate of inflation in a two country model keeping the average markup and allowing price stickiness to differ between countries. There are two channels that govern the optimal rate of inflation. First, with local currencies an inflation tax is partly imposed on the foreign country, so it is optimal to inflate. Second, the average markup constitutes a cost of holding money so it is optimal to deflate, to compensate this cost. The paper has four novel findings: 1) in the local currencies regime the first motive dominates and the optimal inflation is positive. 2) In a monetary union the first motive is absent and the optimal inflation is negative and below the Friedman rule. 3) A monetary union improves global welfare even when stickiness is different in two countries. However, when this difference is large, only one country (the one with higher stickiness) benefits from the integration. 4) A monetary union can be welfare improving for each of both countries, if a transfer is introduced from the more sticky to the more flexible country of (depending on the parameters up to) $2 \%$ of its GDP.
\end{abstract}

Keywords: monetary union, international spillovers, monetary policy

JEL Classification: E52, F41, F42

*I would like to thank Árpád Ábrahám, Russell Cooper and Evi Pappa for all their advice and constant support. The paper has benefited from discussions with seminar participants in the Cardiff Business School and at the EUI in Florence.

${ }^{\dagger}$ Aberconway Building, Colum Drive, Cardiff CF10 3EU, United Kingdom E-mail address: PaczosW@cardiff.ac.uk URL: https://sites.google.com/site/wpaczos/ 


\section{Introduction}

In this paper I ask two half-century-old questions. The first one is about the optimal rate of inflation. In a New Keynesian literature firms are monopolistically competitive and price stickiness is the main transmission channel of a monetary policy. An inflation rate affects real variables (consumption, labor supply and output) through both of these frictions. Therefore both are important to determine the optimal rate of inflation. However, the New Keynesian literature almost exclusively relies on the assumption of zero steady-state inflation. In this steady-state the average markup is constant and independent of an inflation rate, therefore one of the frictions is effectively assumed away. I lift this assumption and look for the optimal steady-state inflation in a simple two-country model of overlapping generations. The two countries setup allows me to study optimal outcomes under two different regimes: local currencies and a monetary union ${ }^{1}$.

In the local currencies economy there are two effects that determine the optimal rate of inflation. One is an international dimension of an inflation tax (the spillover effect) and the other one is that the average markup depends on the rate of inflation (the markup effect). The spillover effect works in the following way. Inflation reduces a return on money holdings. This reduces labor supply. The gain from inflation, increased utility from leisure, lies entirely within the economy. The cost of inflation, the reduced return from money holdings, is however spread across the two economies, as foreigners also hold the domestic currency (cash in advance) to buy imports. This creates an inflationary pressure in an economy with local currency. Like in Cooper and Kempf (2003) the local monetary authority finds it optimal to manipulate the terms of trade and create excessive inflation.

The markup effect works similarly to the Friedman rule. Friedman (1969) argued that the optimal rate of inflation should equalize costs and benefits of holding money. The real interest rate is the opportunity cost of holding money. As long as the real interest rate is positive the optimal rate of inflation should be negative, to compensate for this cost. In this paper the real interest rate is zero, but the average markup constitutes a real cost of holding money. The markup effect therefore creates a disinflationary pressure in an economy. For plausible parameter values the spillover effect dominates the markup effect in the economy with a local currency and optimal inflation is always positive.

In a monetary union however, the spillover effect is absent. The common monetary authority fully internalizes international spillovers and incentives to exploit the inflation tax disappear. The common monetary authority only cares about the average markup. Therefore, in a monetary union optimal inflation is always negative and, when price stickiness is symmetric in both countries, equal to one minus the average markup, that is below the Friedman rule. The monetary union setup can also be interpreted as a model of a closed economy. Schmitt-Grohe and Uribe (2010) provide an excellent review of state-of-the-art literature and some new findings on the optimal rate

\footnotetext{
${ }^{1}$ In this paper these settings correspond to other settings often studied in the literature: cooperation vs non-cooperation and flexible exchange rates vs. fixed exchange rates.
} 
of inflation. They identify the striking puzzle that available theories consistently imply that the optimal rate of inflation ranges from the Friedman rule to numbers insignificantly above zero, which is at odds with the empirical regularity regarding the size of the inflation targets around the world. This paper reinforces this puzzle by showing, among other things, that in a closed economy (or in a monetary union) with monopolistic competition and sticky prices the optimal rate of inflation is in fact below the Friedman rule. One of the novel contributions of SchmittGrohe and Uribe (2010) is the proof that in a closed economy with sticky prices and monopolistic competition (and without a production subsidy ${ }^{2}$ ) the optimal rate of inflation is in fact zero. This result is in stark contrast to Paustian and Stoltenberg (2008) and Khan et al. (2003), which show that the negative trend inflation according to the Friedman rule yields higher welfare than the zero-inflation. This is further reinforeced by the fact that the latter two contributions assume production subsidy, which, if anything, increases the level of steady-state optimal inflation. The result in my paper is in line with those two contributions. Because I do not assume any production subsidies, in my model the optimal rate of inflation is in fact below the Friedman rule. Later in the paper I explain the possible reason of the discrepancy of the mentioned results. All three mentioned papers however, deal with a closed economy setup. In contrast, this paper assumes two countries setup, which is suitable to study the trade-off between the average markup and inflation tax channels.

The two countries setup is also suitable to study the second, half-century-old question: are monetary unions optimal? It may seem that the large existing body of literature has exploited this question in every dimension. In a classical trade-off first formulated by Friedman (1953) and Mundell (1961), the benefit of a monetary union over a flexible exchange rates regime is the reduction in transaction costs, while the cost is the inability of a country to respond to its idiosyncratic shocks. In the Mundellian view the benefits from elimination of a currency conversion and nominal exchange rate fluctuations would encourage more integration in goods and capital markets. Both the upside and the downside of a Mundell-Friedman argument has been largely extended and widely studied in theory and in practice ever since. This paper focuses on the upside of this argument. The common monetary authority internalizes the interdependence of the two economies, the spillover effect disappears and joint welfare goes up.

Surprisingly however, the role of price stickiness on the optimal design of a monetary union has not yet been studied in detail. In a New Keynesian literature, where price stickiness is the main transmission channel of a monetary policy, the same level of stickiness is a common assumption in modes of an open economy ${ }^{3}$. A notable exception is Liu and Pappa (2008), who study gains from a monetary policy coordination when sectoral composition is different in two countries and (among other things) sectors may have different price stickiness. In their paper gains from coordination are significant and due to a fact, that a single social planner can eliminate terms-of-trade externality that individual policymakers overlook. In this paper it corresponds to the elimination of the spillover

\footnotetext{
${ }^{2}$ Starting with Rotemberg and Woodford (1999) it is common in the DSGE literature to undo the monopolistic competition distortion by a small production subsidy that renders steady-state efficient.

${ }^{3}$ See for example Clarida et al. (2001), Clarida et al. (2002), Pappa (2004), citeGM2008.
} 
effect. Also, as Liu and Pappa (2008) study a policy coordination rather than a monetary union, a single social planner is able to set subsidies individually for each sector in each country. In this paper a common monetary authority only sets a common inflation rate. When the assumption of symmetric price stickiness is lifted, gains from a monetary union are distributed unevenly. The country with more sticky prices benefits more from the monetary integration than the country with more flexible prices. When the difference is large, only one country benefits.

With the asymmetric stickiness the optimal choice of inflation in the local currencies regime differs between the countries. The country with higher price stickiness faces a stronger contraction bias and chooses lower inflation in equilibrium than the country with more flexible prices. In a monetary union inflation is reduced in both countries, as the spillover effect is removed. When the difference between the price stickiness between the two economies is high, a monetary union could in fact reduce welfare in the more flexible economy, as the optimal rate of inflation in the union is inefficiently low. The country with higher price stickiness reaps all the benefits of integration at the expense of the more flexible country. From the joint welfare perspective however, a monetary union is always strictly welfare improving. Therefore joining the union could also be sustained as an optimal choice for the economy with more flexible prices if coupled with a lump sum transfer from the economy with more sticky prices, who is a net beneficiary of an integration. The integration with a compensating transfer is therefore a Pareto improvement upon the local currencies regime. For plausible parameter values the size of this transfer is never greater than $2 \%$ of output of the contributor country.

In this paper high inflation in the local currencies regime can be viewed as an example of a free-rider problem as in Cooper and Kempf (2003), where inflation arises as a suboptimal equilibrium solution to the game between two monetary authorities and not between a central bank and private agents, as in Alesina and Barro (2002). In this paper monetary authorities, both in the local currencies and in the monetary union regime do not have any commitment problem. Creating a monetary union enables the single monetary authority to overcome this free-riding problem and reduces inflation to the welfare-maximizing level. The novelty of this paper is generalizing Cooper and Kempf (2003) framework by introducing sticky prices.

There is a large body of the New Open Economy Macroeconomics literature that studies the issue of a monetary cooperation and unions under sticky prices. Pappa (2004) studies the optimal monetary policy arrangements under cooperation, non-cooperation and union subject to technology shocks. She finds that monetary cooperation is welfare improving, however, countries are assumed to have same level of price stickiness and the model is evaluated around the zero steady-state inflation. I generalize her result by showing what happens when the two assumptions are relaxed.

Finally, I rely on the empirical evidence of price stickiness offered by Dhyne et al. (2005) and Dhyne et al. (2009) who estimate price change frequencies and offer different indicators on price stickiness measures for the Euro 
area countries. They find that prices change infrequently and that there is substantial degree of heterogeneity in frequency of price changes across products and countries. Table 1 shows that the differences in the average monthly frequency of price changes in the Eurozone countries can be as high as double. This is the reason to allow for the possibility of asymmetric price stickiness in the model.

The remainder of this paper is organized as follows. In the next section I derive competitive equilibrium outcomes of an open economy given inflation rate. Section 3 studies the optimal inflation rate in an economy with local currency. Section 4 studies the optimal inflation rate and welfare gains in a monetary union. Section 5 shows how the monetary union can be Pareto improving upon the local currencies regime when price stickiness in the two countries is highly asymmetric. Last section concludes.

Table 1: Monthly frequency of price adjustment (in \%) across some Eurozone countries

\begin{tabular}{|c|c|}
\hline Country & Frequency \\
\hline Germany & 13.5 \\
Spain & 13.3 \\
France & 20.9 \\
Italy & $\mathbf{1 0 . 0}$ \\
Portugal & $\mathbf{2 1 . 1}$ \\
\hline
\end{tabular}

\section{The model}

The aim of this paper is to study the consequences of a price stickiness on optimal conduct of monetary policy under local currencies and monetary union regimes. I build a two-country overlapping generations model with monopolistically competitive firms and nominal rigidity in the form of the staggered price adjustment as in Calvo (1983). Firms facing dynamic Calvo-type rigidities are optimizing as in Yun (1996), Woodford (2011) and King and Wolman (2013). Consumers are active in two periods. In first period they work, in second period they consume. The only mean to transfer labor revenues to the next period is through paper money. This generates money demand in the model economy. Both countries are populated by continuum of homogeneous agents. Consumers consume goods manufactured both at Home country and Foreign country. Labor is immobile. At time zero a monetary authority commits to a stable (time independent) money supply growth rate. Changes in money supply come as lump sum transfers for an old generation and are perfectly anticipated by a young generation. Two countries can differ in the level of price stickiness. Throughout the analysis I will denote real variables with lower case letters and 
Table 2: Timing within a period in Home country

\begin{tabular}{l|l|l} 
Firms & Young & Old \\
\hline Signal to update prices & & Receive money transfer \\
Set prices & Supply labor & Demand goods \\
Produce & Get paid in Home currency & Exchange currencies for Home and Foreign goods \\
& Exchange currencies &
\end{tabular}

nominal variables with capital letters. Foreign variables are denoted by a $*$ and the derivations for foreign variables are skipped whenever possible. The timing of events in Home country within one period is presented in Table 2.

Total consumption by Home consumers is an aggregate of consumptions of Home and Foreign goods:

$$
c_{t}=\left(c_{t}^{h}\right)^{\theta}\left(c_{t}^{f}\right)^{1-\theta}
$$

where $\theta$ is a parameter representing home bias in consumption. Both Home and Foreign consumption are aggregates over differentiated goods produced across firms indexed by $z$ :

$$
c_{t}^{i}=\left(\int_{0}^{1} c_{t}^{i}(z)^{\frac{\epsilon-1}{\epsilon}} d z\right)^{\frac{\epsilon}{\epsilon-1}} \quad i=\{h, f\}
$$

where $\epsilon \geq 0$ is elasticity of substitution among differentiated goods. In next sections I analyze price setting behavior of firms and labor supply and consumption decisions of individuals.

\section{$2.1 \quad$ Firms}

In each country there is a continuum of monopolistically competitive firms producing differentiated goods. Each firms sells its goods to consumers in both Home and Foreign country. Each firm faces two demand schedules (from Home and Foreign consumers) given by individuals' solution to their expenditure minimization problem:

$$
\begin{gathered}
c_{t}^{h}(z)=\left(\frac{P_{t}(z)}{P_{t}}\right)^{-\epsilon} c_{t}^{h} \\
c_{t}^{h^{*}}(z)=\left(\frac{P_{t}^{*}(z)}{P_{t}^{*}}\right)^{-\epsilon} c_{t}^{h^{*}}
\end{gathered}
$$

where $c_{t}^{h}(z)$ and $c_{t}^{h^{*}}(z)$ are the demands for Home variety $z$ from Home and Foreign consumers. Home demand for variety $z$ is a function of an aggregate demand $c_{t}^{h}$ for Home goods by Home consumers, a relative price of variety $z$ $\frac{P_{t}(z)}{P_{t}}$ and the elasticity of substitution $\epsilon$.

Firms are assumed to be able to change their price only in specific states of nature and must satisfy all demand at a quoted price. Each period every firm faces probability $1-\lambda$ that it will be able to adjust its price: 


$$
P_{t}(z)= \begin{cases}P_{t-1}(z) & \text { with prob. } \lambda \\ P_{t}^{\#}(z) & \text { with prob. } 1-\lambda\end{cases}
$$

where $P_{t}^{\#}(z)$ is an optimal price that a firm sets when it receives the signal to reset. Since there is a chance that a firm will face the same price for many periods, the pricing problem becomes dynamic. Firms will discount profits $j$ periods into the future by $\Delta_{t, j} \lambda^{j}$, where $\Delta_{t, j}$ is a discount factor and $\lambda$ is the probability of not updating next period. As money is the only store of value, the proper discount factor in this economy is the reverse of gross inflation:

$$
\Delta_{t, j}=\frac{1}{(1+\pi)^{j}} .
$$

When updating its price each firm maximizes the discounted sum of future real profits:

$$
\max _{P_{t}^{\#}(z)} E_{t} \sum_{j=0}^{\infty} \Delta_{t, j} \lambda^{j}\left(\frac{P_{t}^{\#}(z) y_{t+j}(z)}{P_{t+j}}-\frac{W_{t+j} n_{t+j}(z)}{P_{t+j}}\right)
$$

subject to (2.2), (2.3), linear production function:

$$
y_{t}(z)=n_{t}(z)
$$

and imposing that output equals demand at both country and product level:

$$
\begin{aligned}
y_{t}(z) & =c_{t}^{h}(z)+c_{t}^{h^{*}}(z) \\
y_{t} & =c_{t}^{h}+c_{t}^{h^{*}} .
\end{aligned}
$$

From the first order condition each updating firm will choose the same reset price $P_{t}^{\#}$, so that firm index $z$ can be dropped:

$$
P_{t}^{\#}=\frac{\epsilon}{\epsilon-1} \frac{E_{t} \sum_{j=0}^{\infty} \Delta_{t+j} \lambda^{j} W_{t+j} P_{t+j}^{\epsilon-1} y_{t+j}}{E_{t} \sum_{j=0}^{\infty} \Delta_{t+j} \lambda^{j} P_{t+j}^{\epsilon-1} y_{t+j}} .
$$

In a stationary steady state with a constant rate of inflation equation 2.8 reduces to:

$$
P^{\#}=\frac{\epsilon}{\epsilon-1} W .
$$

A firm that is able to reset its price optimally in a given period would charge a constant markup over marginal cost, which I define it as the marginal markup: $\mu_{t}^{*}=\frac{\epsilon}{\epsilon-1}$. A fact that a firm's pricing decision is in fact static is a direct conseqence of the CES preference structure. Each period all producers share the same cost structure and 
face the same, due to CES preferences static demand schedule. Hence, their optimal pricing decision is not only symmetric but also static ${ }^{4}$.

In an inflationary equilibrium however, the average markup $P_{t} / W_{t}$ is different than the marginal markup, as prices are sticky. This stochastic price setting specification results in a stationary distribution of firms in terms of the time since their last price adjustment. The fraction of firms that last adjusted $j$ periods ago is $\phi_{j}=(1-\lambda) \lambda^{j}$. Thus, aggregate price level evolves according to:

$$
P_{t}=\left(\sum_{j=0}^{\infty} \phi_{j}\left(P_{t-j} \#\right)^{1-\epsilon}\right)^{\frac{1}{1-\epsilon}}
$$

or, more simply:

$$
P_{t}=\left((1-\lambda)\left(P_{t}^{\#}\right)^{1-\epsilon}+\lambda\left(P_{t-1}\right)^{1-\epsilon}\right)^{\frac{1}{1-\epsilon}} .
$$

I define the average markup $\mu_{t}$ as aggregate nominal price to nominal wage. I can rewrite average markup as:

$$
\mu_{t}=\frac{P_{t}}{W_{t}}=\frac{P_{t}}{P_{t}^{\#}} \frac{P_{t}^{\#}}{W_{t}}
$$

where the first expression I define as "price adjustment gap" and the second expression is given by the marginal markup. In an inflationary steady-state by evaluating (2.9) in a situation where both $P_{t}$ and $P_{t}^{\#}$ grow at the same rate $\pi$ I obtain the formula for price adjustment gap:

$$
\frac{P_{t}}{P_{t}^{\#}}=\left(\frac{1-\lambda(1+\pi)^{\epsilon-1}}{1-\lambda}\right)^{\frac{1}{\epsilon-1}} .
$$

Then the average markup is:

$$
\mu=\frac{\epsilon}{\epsilon-1}\left(\frac{1-\lambda(1+\pi)^{\epsilon-1}}{1-\lambda}\right)^{\frac{1}{\epsilon-1}} .
$$

Average markup in this economy is time-independent, goes down with inflation, goes up with price stickiness when inflation is negative and goes down with price stickiness when inflation is positive. Figure 1 plots how the average markup changes with inflation and stickiness. For the firms to generate non-negative profits average markup must be no lesser than one. The necessary and sufficient condition for this is given by 2.13 . This condition will limit the choice of inflation rates studied in the next chapter.

$$
\pi \leq \lambda^{\frac{1}{1-\epsilon}}\left(1-\left(\frac{\epsilon}{\epsilon-1}\right)^{1-\epsilon}(1-\lambda)\right)^{\frac{1}{\epsilon-1}}-1
$$

With firms behaving as explained, monetary authority can in principle use inflation to undo the friction caused by monopolistic competition. With prices sticky enough higher levels of inflation $\pi$ result in smaller 'price adjustment gap'.

\footnotetext{
${ }^{4}$ A notable example of departure from CES is Bergin and Feenstra (2000), who show that Calvo rigidity under translog demand structure implies a price-setting rule that is dynamic and gives weight to prices set by competitors.
} 
Figure 1: Inflation and average markup at different $\lambda$ levels

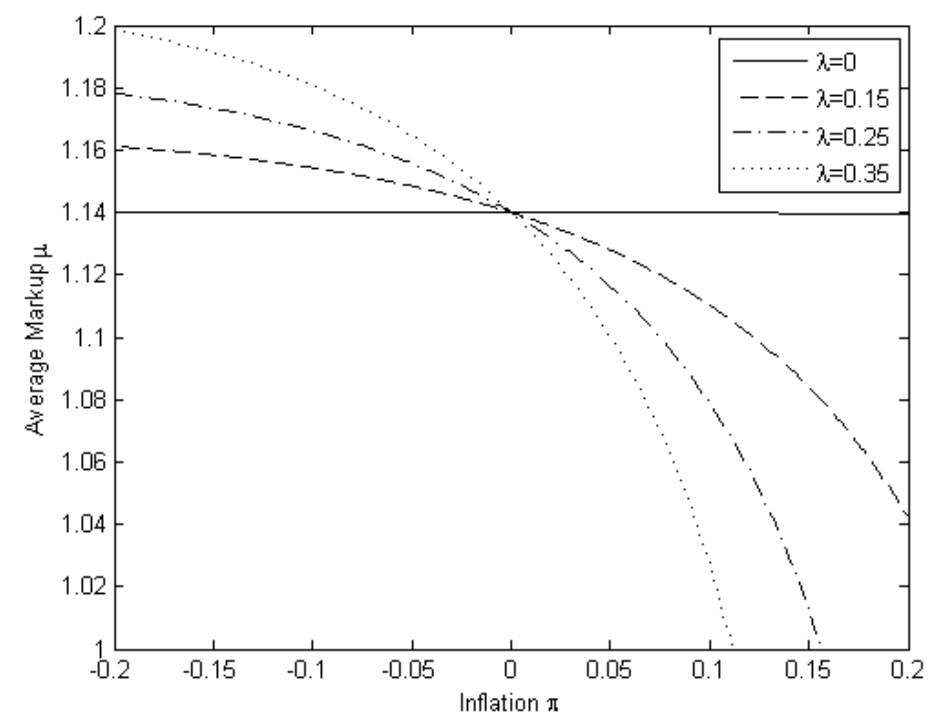

\subsection{Households}

Households are active in two periods. In first period households supply labor to firms, receive wages and profits and choose levels of Home and Foreign money holdings. In the second period they consume Home and Foreign goods. The optimization problem of a representative household in Home country is given by

$$
\max _{m_{t}^{h}, m_{t}^{f}, n_{t}} E_{t}\left(\log \left(c_{t+1}\right)-g\left(n_{t}\right)\right)
$$

subject to (2.1) and first and second period budget constraints:

$$
\begin{gathered}
W_{t} n_{t}+\Pi_{t}=m_{t}^{h}+e_{t} m_{t}^{f} \\
c_{t+1}^{h}=\frac{m_{t}^{h}+\tau_{t+1}}{P_{t+1}} \quad c_{t+1}^{f}=\frac{m_{t}^{f}}{P_{t+1}^{*}}
\end{gathered}
$$

where $m_{t}^{h}$ are Home money holdings, $m_{t}^{f}$ are Foreign money holdings, $\Pi_{t}$ is an average nominal profit of Home firms, $\tau_{t+1}$ is Home lump sum money transfer from the monetary authority, $P_{t+1}$ and $P_{t+1}^{*}$ are aggregate nominal prices of Home goods and Foreign goods in local currecies and $e_{t}$ is the exchange rate. Labor disutility function $g\left(n_{t}\right)$ is assumed to be increasing and convex. Taste preference for home goods $\theta$ is assumed to be constant and same for both countries $\theta \in[0,1]$ with $\theta>0.5$ representing the home bias. 
First order conditions with respect to Home and Foreign money holdings yield the following Euler equation:

$$
\frac{1-\theta}{e_{t} m_{t}^{f}}=\frac{\theta}{m_{t}^{h}+\tau_{t+1}^{h}}
$$

which implies that future money supply will be held in constant proportions between currencies by the old generation. This in turn implies, that every period old generation would consume constant fraction of home output. With respect to labor supply FOC gives:

$$
g^{\prime}\left(n_{t}\right)=\frac{\theta W_{t}}{m_{t}^{h}+\tau_{t+1}^{h}}=\frac{\theta W_{t}}{P_{t+1} c_{t+1}^{h}}
$$

\subsection{Market clearing}

In every period three markets clear in each country: goods market, labor market, money market and one international foreign exchange market. Goods market clearing in Home country is given by (2.7). Labor market clears:

$$
n_{t}=\int_{0}^{1} n_{t}(z) d z .
$$

where $n_{t}$ is solution to individuals FOC on labor supply (2.18). Monetary authority supplies money, which is held by old generation, who spends it on consumption goods and then firms divide it between wages and profits:

$$
M_{t}=P_{t}^{h}\left(c_{t}^{h}+c_{t}^{h *}\right)=W_{t} n_{t}+\Pi_{t}
$$

The evolution of money stocks at Home country is given by

$$
M_{t+1}=M_{t}(1+\sigma)
$$

where $\sigma$ is fixed growth rate of home money supply. In next section, it will become decision variable for monetary authority and is taken by agents as given. Additional money supply finances lump-sum transfers to home old generation agents:

$$
\tau_{t+1}=\sigma M_{t}
$$

Exchange market clears:

$$
m_{t}^{* h}=e_{t} m_{t}^{f}
$$

Finally, the stock of each currency after the exchange market closes is distributed between home and foreign agents according to:

$$
M_{t}=m_{t}^{h}+m_{t}^{* h}
$$




\subsection{Equilibrium}

Given the conditions for optimization by agents and market clearing conditions in two countries I first characterize optimal steady-state levels of employment and consumption given stable money growth rates. A monetary stationary rational expectations equilibrium is given by labor supply functions $\left(n_{t}, n_{t}^{*}\right)$, consumption functions $\left(c_{t}^{h}, c_{t}^{f}, c_{t}^{* h}, c_{t}^{* f}\right)$ and system of price expectations $\left(P_{t}, P_{t}^{*}, e_{t}\right)$ such that agents optimize and markets clear. Equations (2.16), (2.17), (2.20), (2.21) and (2.23) give the following:

$$
m_{t}^{h}+\tau_{t+1}^{h}=\theta(1+\sigma) M_{t}
$$

This together with budget constraint (2.16), goods market clearing (2.7), production function (2.5) and money market clearing (2.20) imply that consumption in equilibrium is:

$$
\begin{array}{r}
c_{t}^{h}=\theta n_{t} \\
c_{t}^{f}=(1-\theta) n_{t}^{*}
\end{array}
$$

Domestic consumption is therefore always a fixed fraction of domestic output. This stationary property of consumption combined with money market clearing (2.20) and evolution of money stock implies equilibrium property of price evolution:

$$
P_{t+1} \stackrel{\text { def }}{=} P_{t}(1+\pi)=P_{t}(1+\sigma)
$$

which shows that money is neutral in the long run as $\pi=\sigma$. Changes is money supply $M_{t}$ only affect prices $P_{t}$. Last two equations combined with FOC on labor supply (2.18), stationary property of equilibrium and definition of average markup (2.10) imply stationary level of labor supply. Because of the stationarity time indices can be dropped:

$$
g^{\prime}(\bar{n}) \bar{n}=\frac{1}{\mu(1+\sigma)}
$$

where $\bar{n}$ stands for steady-state equilibrium level of labor supply. In steady-state equilibrium labor and consumption of Home and Foreign goods in both countries and exchange rate are constant and home and foreign prices grow at the rates $\sigma$ and $\sigma^{*}$. Equilibrium condition (2.28) reveals interesting properties. The model manifests long run neutrality of money (as permanent changes in quantity of $M$ only affect prices and not output) but not superneutrality. There will be real effects of sustained long run inflation stemming from two sources: the average markup and the inflation tax.

Proposition 1. Inflation has two equilibrium effects on real activity. It increases labor supply and consumption through a decreased level of the average markup and decreases labor supply and consumption through the inflation tax. 
Proof. First part of proposition derives from equations (2.10) and (2.11). Second part of proposition follows from convexity of $g(n)$.

This result differs significantly from Cooper and Kempf (2003), where under flexible prices, positive money growth rate worked only as an inflation tax, decreasing steady-state optimal labor supply. This proposition shows that in the sticky prices environment there are two effects of monetary policy working in opposite directions. First, the inflation tax effect (which works similarly to long term Phillips curve) discourages agents from work, so they optimally choose lower labor supply level. Second, the average markup effect (which works similarly to short term Phillips curve) derives from the fact that prices at firm level move infrequently. In non-reseting firms with higher inflation costs rise faster. They take wages as given and must satisfy all demand at posted price, so they need to cut their profits, which results in lower average markups and higher average output. In the remainder of the paper, wherever it is necessary to impose functional form on the labor disutility function I use the following specification:

$$
g(n)=\frac{1}{2} n^{2} .
$$

From (2.28) and $\pi=\sigma$ optimal labor supply reads:

$$
\bar{n}(\sigma)=\left(\frac{\epsilon}{\epsilon-1}\left(\frac{1-\lambda(1+\sigma)^{\epsilon-1}}{1-\lambda}\right)^{\frac{1}{\epsilon-1}}(1+\sigma)\right)^{-\frac{1}{2}}
$$

To calculate the net effect of inflation on labor supply I first evaluate first derivative of 2.30 and later plot how optimal labor supply reacts to inflation and stickiness in Figure 2.

$$
\frac{\partial \bar{n}(\sigma)}{\partial \sigma}=\underbrace{-\frac{1}{2}\left(\frac{\epsilon}{\epsilon-1}\right)^{-\frac{1}{2}}}_{<0} \underbrace{(1+\sigma)^{-\frac{3}{2}}}_{>0} \underbrace{\left(\frac{1-\lambda(1+\sigma)^{\epsilon-1}}{1-\lambda}\right)^{-\frac{1}{2(\epsilon-1)}}}_{>0 \text { since }(2.13) \text { holds }} \underbrace{\left(1-\frac{\lambda(1+\sigma)^{\epsilon-1}}{1-\lambda(1+\sigma)^{\epsilon-1}}\right)}_{\lessgtr 0} .
$$

From (2.31) it follows that the sign of the derivative depends on the sign of the expression in the last parenthesis. The first effect (inflation tax or long-term Phillips curve) will therefore dominate, so the labor supply will decrease with inflation, whenever:

$$
\sigma<\left(\frac{1}{2 \lambda}\right)^{\frac{1}{\epsilon-1}}-1
$$

and the second effect (sticky prices or short-term Phillips curve effect) will dominate, so the labor supply will increase with inflation, whenever the reverse is true. This can be easily seen in Figure 2. When prices are flexible $\lambda=0$ condition 2.32 is always met, so optimal labor supply decreases in inflation. When prices are sticky $\lambda>0$ the above condition is only met for some values of $\sigma$. For example, when marginal markup is equal to 1.14 (which gives $\epsilon=8.14$ ) and $\lambda=0.15$ labor supply goes down with inflation up to $\sigma=0.18$. Higher inflation decreases return on money holdings and this discourages households from supplying labor. Inflation tax effect dominates. Above this 
Figure 2: Inflation and optimal labor supply at different $\lambda$ levels

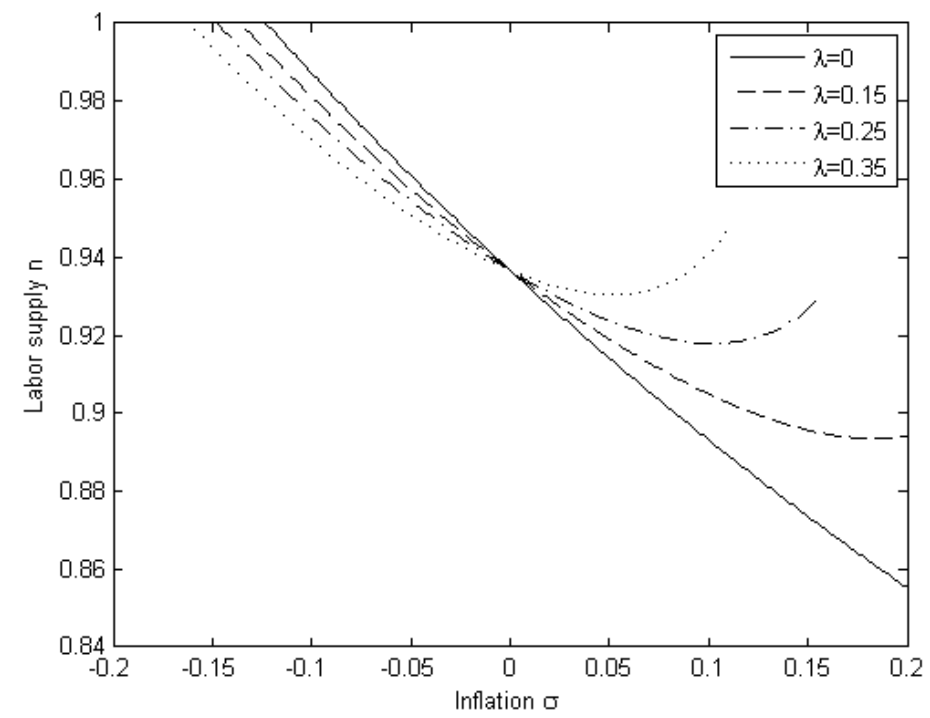

point the average markup effect dominates. Higher inflation reduces average markup in the economy, which in turn increases return on money. For $\lambda=0.25$ and $\lambda=0.35$ this switch occurs at $\sigma=0.11$ and $\sigma=0.05$.

It can be easily shown, that condition (2.32) is always more restrictive than (2.13) so that both relationships are possible within the support of $\sigma$. This result has profound consequences on optimal money supply rules chosen by monetary authorities, the topic I turn to next.

\section{Optimal Monetary Policy with Local Currencies}

In this section I look for the rate of inflation that solves the monetary authority optimization problem. By manipulating the rate of growth of the monetary base local monetary authority chooses a steady state which yields highest welfare for households and it takes equilibrium outcomes and market clearing conditions as constraints:

$$
V\left(\sigma, \sigma^{*}\right)=\max _{\sigma}(u(c)-g(n))
$$

subject to optimal consumption decision (2.25) and optimal labor supply decision (2.30). Substituting in we get:

$$
V\left(\sigma, \sigma^{*}\right)=\max _{\sigma}\left\{\theta \log \theta+\theta \log (\bar{n}(\sigma))+(1-\theta) \log (1-\theta)+(1-\theta) \log \left(\bar{n}^{*}\left(\sigma^{*}\right)\right)-g(\bar{n}(\sigma))\right\} .
$$

Foreign country monetary authority optimization problem is symmetric. First order condition for the problem 
reads:

$$
\frac{\theta}{n(\sigma)} \bar{n}^{\prime}(\sigma)-g^{\prime}(\bar{n}(\sigma)) \bar{n}^{\prime}(\sigma)=0
$$

The above condition combined with optimal labor supply condition 2.28 gives the following two roots:

$$
\begin{array}{r}
\frac{1}{\mu\left(\sigma_{1}\right)\left(1+\sigma_{1}\right)}=\theta \\
\bar{n}^{\prime}\left(\sigma_{2}\right)=0 .
\end{array}
$$

The problem is highly non-linear therefore I proceed by solving two simplified benchmark cases first. The first benchmark is the economy with no frictions (perfect competition and flexible prices). The second benchmark is the economy with only one friction (monopolistic competition). Both benchmarks have closed form solutions. After that I proceed with the third, full benchmark case, that is the economy with both frictions (monopolistic competition and sticky prices).

\section{Benchmark 1. Open economy with flexible prices and perfect competition}

This economy is analogous to Cooper and Kempf (2003). Prices are flexible $(\lambda=0)$ and average and marginal markups are equal to one $(\mu=1)$.

Proposition 2. In the economy with flexible prices and perfect competition first order condition (3.3) of the monetary authority optimization problem has only one solution, $\sigma_{1}$ in (3.4). Optimal rate of inflation maximizing households utility is therefore:

$$
\sigma^{B 1}=\frac{1-\theta}{\theta}
$$

Proof. See Appendix.

Solution to (3.5) yields $\sigma_{2}=-1$, which is outside of the support for sigma and would bring an immediate collapse of the economy, with no exchange, no production and no consumption.

With positive rate of inflation monetary authority exploits international spillovers to run inflationary, 'beggarthy-neighbor' policy. Both labor supply and home output is lower than under no inflation. However, fraction of output is consumed abroad, so inflation tax is partly exercised on foreign individuals. Home individuals can enjoy more leisure without paying full cost of lost output. It is worthwhile to notice, that if both Home and Foreign country form monetary union all spillovers are internalized by common monetary authority. There is no possibility to exercise inflation tax on foreign individuals, as there is no 'neighbor to beggar'. It is equivalent to the situation of a closed economy, that is $\theta=1$, so $\sigma^{B 1}=0$. 
Table 3: Parameter Values

\begin{tabular}{|c|c|c|}
\hline Parameter & Description & Value \\
\hline$\epsilon$ & Elasticity of substitution & 8.14 \\
\hline$\theta$ & Home bias in consumption & 0.8 \\
\hline$\lambda$ & Probability that firm will not be able to update & $(0,0.32)$ \\
\hline
\end{tabular}

\section{Benchmark 2. Open economy with flexible prices and imperfect competition}

In this economy the average markup is equal to the marginal markup $\mu=\mu^{\#}=\frac{\epsilon}{\epsilon-1}$ and is independent from the inflation rate. It follows that:

Proposition 3. In the economy with flexible prices and monopolistic competition first order condition (3.3) of the monetary authority optimization problem has only one solution, $\sigma_{1}$ in (3.4). Optimal rate of inflation maximizing households utility is therefore:

$$
\sigma^{B 2}=\frac{1-\mu^{\#} \theta}{\mu^{\#} \theta}
$$

Proof. See Appendix.

It is straightforward to notice that in the imperfect competition economy with flexible prices optimal level of inflation is strictly smaller than in the economy with perfect competition and flexible prices $\bar{\sigma}^{B 2}<\bar{\sigma}^{B 2}$. It is due to the fact that the markup has the same effect on the real economy as inflation tax, it reduces optimal level of labor supply. As the inflation tax and the markup are substitutes, a lower level of inflation is sufficient to achieve optimal level of labor supply satisfying $g^{\prime}(\bar{n}) \bar{n}=\theta$. It may be the case that for a high markup or high openness the optimal level of inflation is negative. Similarly to Benchmark 1 case, the second root of the first order condition is $\overline{\sigma_{2}}=-1$ and is outside of the support for $\sigma$.

In this benchmark case a monetary authority in a monetary union would no longer choose zero, but strictly negative level of inflation $\bar{\sigma}^{B 2}=\frac{1-\mu^{\#}}{\mu^{\#}}$. The intuition holds the same. A monetary authority wants to undo a negative effect of markups on optimal labor supply decision, therefore encourages individuals to work more by imposing a negative inflation tax.

\section{Benchmark 3. Open economy with sticky prices}

On top of the effects documented in the Benchmark 2 scenario now inflation also affects the size of the average markup. As the first order conditions 3.4 and 3.5 do not have analytical solutions I solve the problem numerically. 
I discipline the model with the standard parametrization. The elasticity of substitution $\epsilon$ is equal to 8.14, which results in the marginal markup being equal to 1.14. The second parameter, home bias $\theta$ I set equal to 0.8 , as in Pappa (2004). The stickiness parameter $\lambda$ I vary between 0 and 0.32 to asses how the model diverges from benchmark cases studied before. The value $\lambda=0.32$ is a yearly equivalent of 0.75 on a quarterly basis, a standard stickiness value assumed in a quantitative literature.

Figure 3 plots numerical solution of all three benchmark models of the open economy for the chosen parameter values $\epsilon$ and $\theta$ and varying the stickiness parameter $\lambda$. The optimal level of inflation in Benchmark 3 model is always lower than in the perfect competition (Benchmark 1) model. Intuition behind this result is similar to the one explained in Benchmark 2 case. The existence of the average markup in the economy takes away some of the inflation tax power, as it discourages individuals from supplying labor. Therefore, in the economy with imperfect competition a monetary authority always chooses the lower level of inflation than in the economy with perfect competition.

Comparing to Benchmark 2 for low stickiness $\lambda$ local monetary authority now chooses higher levels of inflation. Labor supply goes up with stickiness and is convex in inflation (see Figure 2). Therefore, to counter increasing labor supply resulting from higher stickiness, local monetary authority decides for higher inflation to decrease labor supply. Consumption rises in stickiness, as average markups are decreasing both in inflation and in stickiness (see Figure 1).

Optimal inflation goes up with stickiness until $\lambda=0.15$ and the optimal rate of inflation is $\sigma_{1}=\sigma_{2}=0.18$. This is a point, where labor supply is at its minimum. Beyond this point 3.4 does not have a solution, so $\sigma_{1}$ does not exist and the maximum of the monetary authority's problem is reached at $\sigma_{2}$, that is where $\bar{n}^{\prime}(\sigma)=0$. For high stickiness the optimal rate of inflation is the one, which minimizes labor supply. Labor supply is still increasing in stickiness, therefore, to counter the effect of increasing stickiness, local monetary authority must now choose the rate of inflation that minimizes labor supply. As is evident from Figure 2 the minimum labor supply point is a decreasing function of stickiness.

\section{Optimal Monetary Policy in a Monetary Union}

The structure of the world economy is the same as before. The only difference is that now the two countries are subject to central monetary policy conducted by a single monetary authority. The monetary authority problem is now different, as it choses only one money supply growth rate equal for both economies in order to maximize

the joint welfare of the two. Let $\sigma^{U}$ be the growth rate of the money stock in the monetary union, then the joint welfare of the two economies $V^{U}$ is:

$$
V^{U}\left(\sigma^{U}\right)=w V\left(\sigma^{U}, \sigma^{U}\right)+(1-w) V^{*}\left(\sigma^{U}, \sigma^{U}\right)
$$


Figure 3: Optimal Inflation with Local Currencies

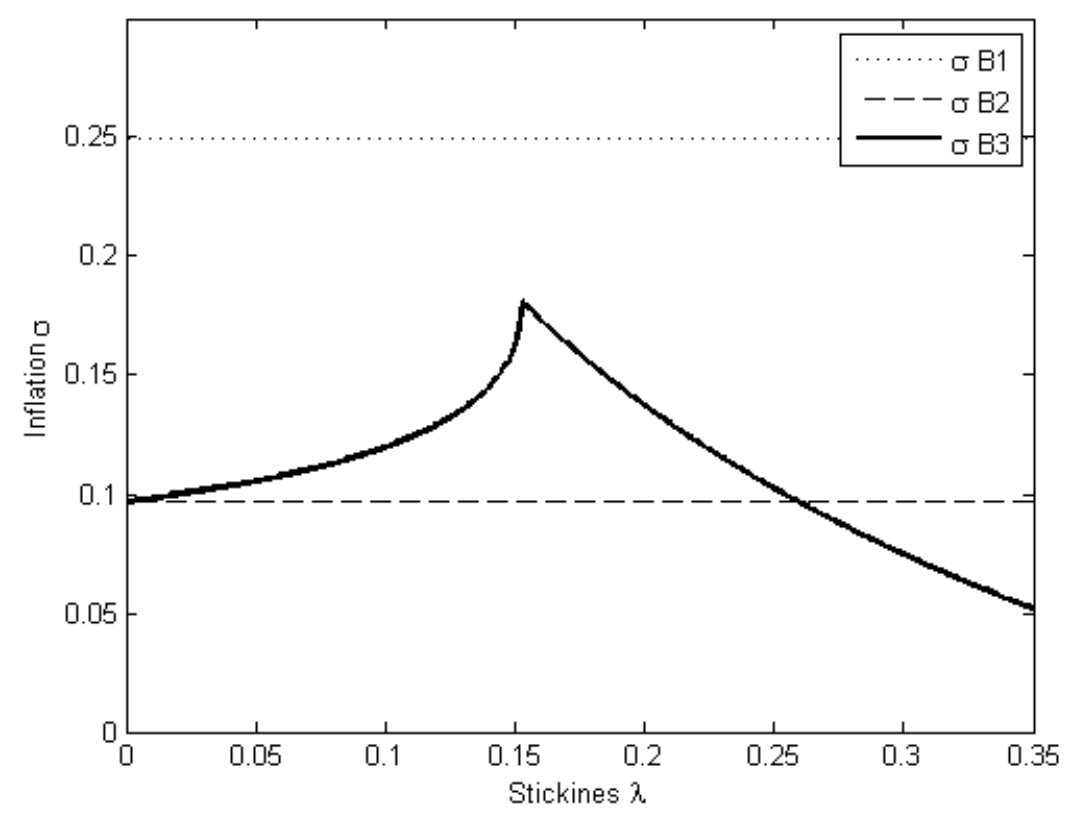

where $w$ is a weight assigned by the single monetary authority to the Home country. The single monetary authority maximizes (4.1) subject to optimal consumption decisions (2.25), (2.26) and optimal labor supply decision (2.30) for both Home and Foreign countries. Substituting in we get:

$$
\begin{aligned}
V^{U}\left(\sigma^{U}\right)=\max _{\sigma^{U}} & \left(\theta \log \theta+(1-w-\theta-2 w \theta) \log \left(\bar{n}\left(\sigma^{U}\right)\right)\right. \\
& +(1-\theta) \log (1-\theta)+(\theta+w-2 w \theta) \log \left(\bar{n}^{*}\left(\sigma^{U}\right)\right) \\
& \left.-w g\left(\bar{n}\left(\sigma^{U}\right)\right)-(1-w) g\left(\bar{n}^{*}\left(\sigma^{U}\right)\right)\right)
\end{aligned}
$$

The first order condition assuming equal weights $w=\frac{1}{2}$ for the problem reads:

$$
\frac{1}{2} \bar{n}^{\prime}\left(\sigma^{U}\right)\left(\frac{1}{\bar{n}\left(\sigma^{U}\right)}-g^{\prime}\left(\bar{n}\left(\sigma^{U}\right)\right)\right)+\frac{1}{2} \bar{n}^{*^{\prime}}\left(\sigma^{U}\right)\left(\frac{1}{\bar{n}^{*}\left(\sigma^{U}\right)}-g^{\prime}\left(\bar{n}^{*}\left(\sigma^{U}\right)\right)\right)=0
$$

As in the previous section, as the problem is highly non-linear, I proceed by solving two simplified benchmark cases first. The first benchmark is the monetary union economy with no frictions (perfect competition and flexible prices). The second benchmark is the monetary union economy with only one friction (monopolistic competition). Both benchmarks have closed form solutions. After that I proceed with the third, full benchmark case, that is 
the monetary union economy with both frictions (monopolistic competition and sticky prices). I split the third benchmark case into two and study the optimal rate of inflation and the welfare gains when price stickiness is symmetric and asymmetric in the two countries.

\section{Benchmark 1. Monetary union with flexible prices and perfect competition}

With $\lambda=\lambda^{*}=0$ Foreign and Home labor supplies are equal. The first order condition (4.3) boils down to:

$$
\bar{n}^{\prime}\left(\sigma^{U}\right)\left(\frac{1}{\bar{n}\left(\sigma^{U}\right)}-g^{\prime}\left(\bar{n}\left(\sigma^{U}\right)\right)\right)=0 .
$$

The above condition gives the following two roots:

$$
\begin{array}{r}
\mu\left(\sigma_{1}^{U}\right)\left(1+\sigma_{1}^{U}\right)=1 \\
\bar{n}^{\prime}\left(\sigma_{2}^{U}\right)=0 .
\end{array}
$$

Proposition 4. In the economy with with flexible prices and perfect competition the optimal rate of inflation in a monetary union is zero and adopting a common currency is welfare improving from both individual and joint welfare perspectives.

$$
\sigma^{B 1 U}=0
$$

Proof. See Appendix.

The common central bank now fully internalizes the spillovers created by the inflationary tax, namely the loss of consumption which happens not only in Home country, but also in Foreign country. So the incentives to inflate are reduced.

In the economy with local currencies there are incentives to distort allocation by imposing inflation tax on the Foreign country. As Foreign country also deviates from efficient solution, the loss of utility not compensated by reduced working hours occurs in both countries. The common monetary authority overcomes this externality. The common central bank internalizes cross-border spillovers from inflation. Without markups it is optimal in a union to not inflate at all.

\section{Benchmark 2. Monetary union with flexible prices and imperfect competition}

With $\lambda=\lambda^{*}=0$ Foreign and Home labor supplies are equal. First order condition (4.3) boils down to (4.4).

Proposition 5. In the economy with with flexible prices and monopolistic competition the optimal rate of inflation in a monetary union is lower than in the local currency economy and adopting a common currency is welfare improving from both individual and joint welfare perspectives.

$$
\sigma^{B 2 U}=\frac{1-\mu^{\#}}{\mu^{\#}}
$$


Proof. See Appendix.

In the economy with constant markups incentives of a local central bank to inflate are reduced. However, as markups discourage individuals from working, it is efficient to impose negative inflation rate to undo this distortion. Another way to see this result is to look directly at the first order condition 4.5. Whenever the markup is higher than one inflation must be negative for the condition to be met. Right hand side of this first order condition can be interpreted as the inverse of the gross interest rate (which is 1 in this model). Left hand side is the cost of holding money. Both the average markup and inflation are costs of holding money. A monetary authority sets negative inflation rate to compensate for the average markup cost of holding money. In such a union inflation is always lower than in the economy with local currency.

\section{Benchmark 3a. Monetary union with symmetric sticky prices}

With $\lambda=\lambda^{*}>0$ Foreign and Home labor supplies are equal. The first order condition (4.3) boils down to (4.4). In the monetary union with sticky prices incentives to 'beggar-thy-neighbor' also vanish, so the optimal level of inflation in the union is always lower than in the local currency economy. However, now the average markup is also a function of inflation. The negative level of inflation increases average markups discouraging individuals from work compared to Benchmark 2.

Proposition 6. In the world economy with symmetric sticky prices and monopolistic competition the optimal rate of inflation in a monetary union is: a) lower than in the local currency economy, b) lower than in the flexible prices monetary union c) lower than the Friedman rule, and adopting a common currency is welfare improving from both individual and joint welfare perspectives.

Proof. The first part of the proof for a) and b) is done numerically and the result is presented in Figure 4, c) follows from the fact, the the gross interest rate in this economy is one, so the Friedman rule would prescribe zero inflation. The optimal inflation in this economy is negative, so it is below Friedman rule. For the proof of the second part of the Proposition see Appendix.

Figure 4 plots numerical solution of the three benchmark models for the chosen parameter values $\epsilon$ and $\theta$ and varying the symmetric stickiness parameter $\lambda$. As incentives to impose inflation tax are removed in a monetary union, the optimal level of inflation is always lower than in the local currencies economy in each respective benchmark and when competition is not perfect it is always negative. To understand this result let us think about a monetary union with symmetric sticky prices as a big closed economy. This allows us to compare this result with the results for the closed economy with the same features presented in Chapter 6 of Schmitt-Grohe and Uribe (2010). As their setup is more general, my results should be a special case of theirs. It is not the case however, as their results say, 
Figure 4: Optimal Inflation in the monetary union with symmetric stickiness $\lambda=\lambda^{*}$

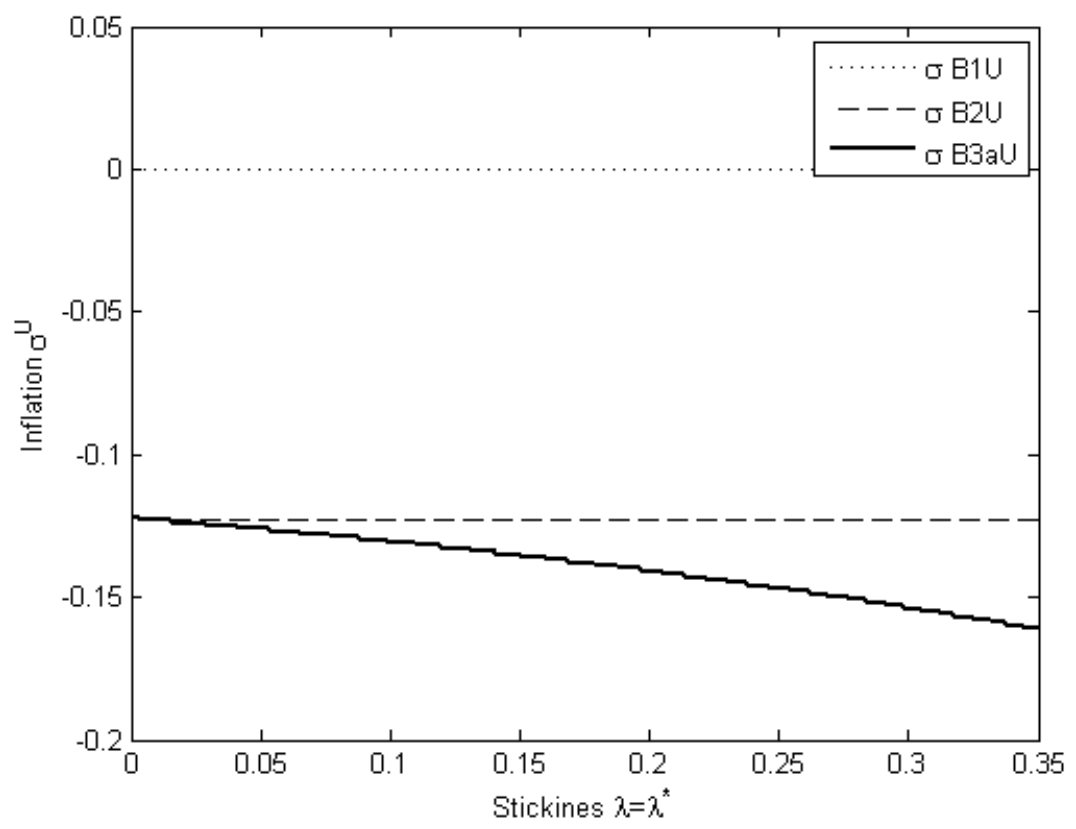

that in a closed economy with monopolistic competition and sticky prices the optimal level of inflation is zero. To start the discussion let us concentrate on the first order condition 4.5, which is presented below for convenience:

$$
\mu\left(\sigma^{U}\right)\left(1+\sigma^{U}\right)=1
$$

and let's think about $\mu$, the average markup, as a distortion, and $\left(1+\sigma^{U}\right)$ as a cost of holding money. In my setup the monetary authority has only one tool, the rate of growth of the monetary stock $\left(\sigma^{U}\right)$, which in equilibrium is equal to inflation. If the monetary authority (or any other authority with a causative power) had an additional instrument that would affect $\mu$ and nothing else, it would use this instrument to set $\mu=1$. Next, as the average markup distortion had been removed from the economy, the authority would set $\sigma=0$, such that benefits of holding money (minus the rate of inflation) are equal to costs (net interest rate, which in this setup is equal to 0). In Chapter 6.2 of Schmitt-Grohe and Uribe (2010) authors consider the economy with production subsidies. These production subsidies are financed by lump sum taxes and can address the average markup distortion, so constitute a perfect candidate instrument that fits the above description.

The Benchmark 3a economy can be interpreted as a special case of Chapter 6.3 of Schmitt-Grohe and Uribe (2010) where authors consider the economy without production subsidies. They claim that in this economy the optimal rate of inflation is also zero. In my Benchmark 3a economy this is not the case, because $\mu\left(\sigma^{U}\right)$ is always 
Figure 5: Optimal Inflation in a Union with Asymmetric Stickiness $\lambda \neq \lambda^{*}$

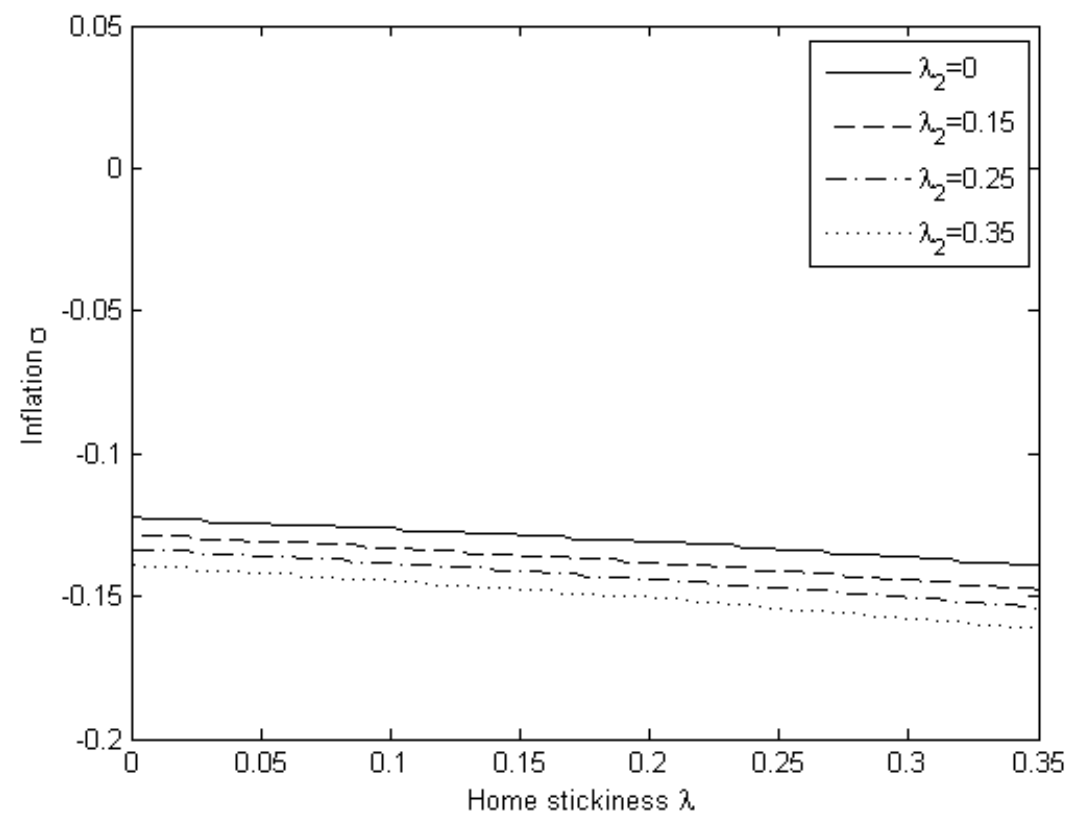

greater than one. The discrepancy of our results can be traced down to the setup of their proof, where they postulate that Ramsey planner maximizes agents' welfare with respect to independently inflation and price dispersion (which in their notation is $\tilde{p}_{t}$ and in my notation would be $\left.\frac{\mu(\sigma)}{\mu^{\#}}\right)$. In this, their Ramsey planner effectively has access to an additional tool, that fits the above description. Absent this second tool the optimal rate of inflation would be strictly negative and below the Friedman rule.

Figure 4 also shows, that the optimal rate of inflation is further decreasing in stickiness. This is because the slope of the average markup as a function of inflation is increasing in stickiness, as can be seen in Figure 1. Therefore, when stickiness goes up, the cost of holding money $\mu(\sigma)$ goes up for any given $\sigma$. To compensate this additional cost the monetary authority increases benefits of holding money, by reducing $\sigma$.

\section{Benchmark 3b. Monetary union with asymmetric sticky prices}

With $\lambda \neq \lambda^{*}$ Foreign and Home labor supplies are not equal. The first order condition (4.3) does not have a closedform solution and the model is solved numerically. The average markup, as in Benchmark 3a is also a function of inflation. The average markup and Home and Foreign labor supply change in $\sigma, \lambda$ and $\lambda^{*}$.

Figure 5 plots numerical solution of the Benchmark 3b economy for the chosen parameter values $\epsilon$ and $\theta$ and varying the asymmetric stickiness parameters $\lambda$ (on the horizontal axis) and $\lambda^{*}$ (four different plots represent four 
Figure 6: Welfare gains and welfare losses from a union with asymmetric price stickiness

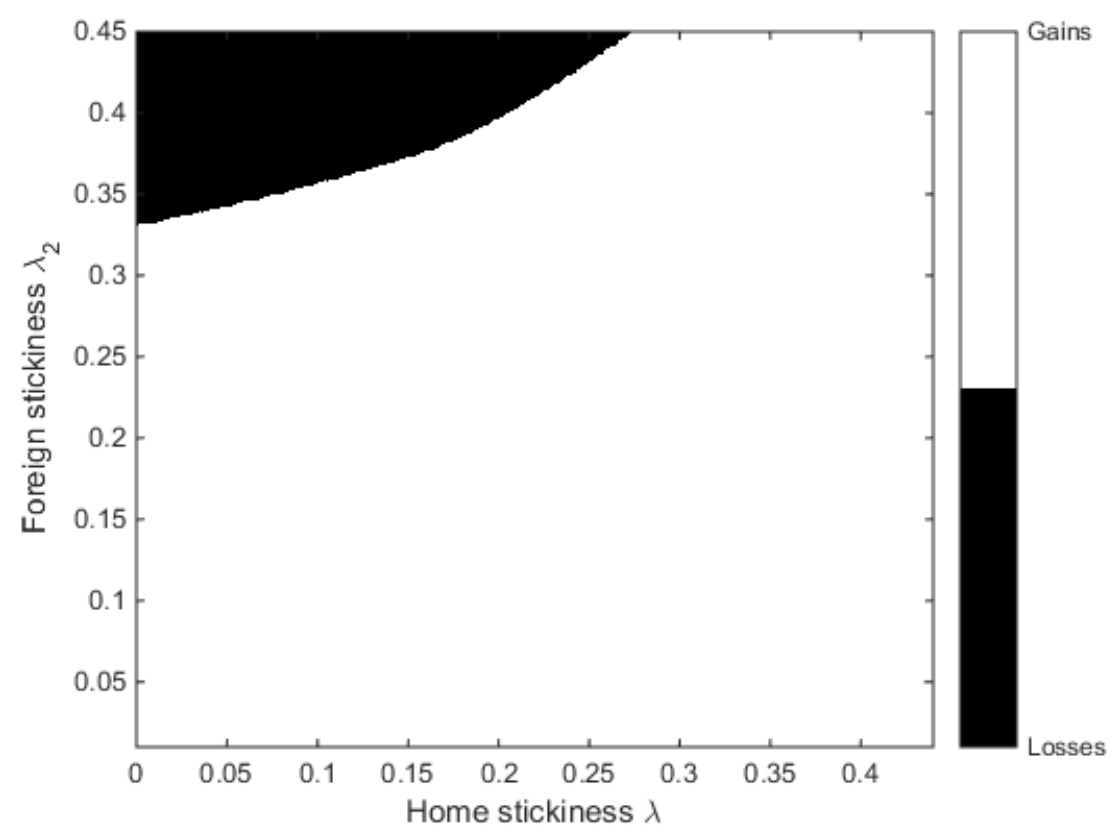

different values of $\lambda^{*}$ ). The optimal rate of inflation in the monetary union economy is decreasing in both Home and Foreign stickiness, as the intuition from the Benchmark 3a would suggest.

Proposition 7. In the economy with imperfect competition and sticky prices adoption of the common currency is not always welfare improving.

Proof. Done numerically. For exposition see Figure 6

Let's focus our attention on a special case where the Home country has flexible prices and the Foreign country has very sticky prices. The optimal level of inflation in the monetary union economy is negative, and below the level that would prevail if the Foreign country was symmetric to the Home country. Under such a high level of deflation the average markup in the Home country increases so much, that the gains from removing inflation tax inefficiencies are not be sufficient to compensate for this loss. This situation is shown in Figure 6 where the Home country with low $\lambda$ experiences a welfare loss after forming a monetary union with the Foreign country that has high $\lambda$. For the cases where stickiness is equal (Benchmark 3a) or relative differences in stickiness are not too large monetary union is welfare improving from the individual welfare perspective. 


\section{$5 \quad$ Reinstating Optimality}

From the Home country's perspective a monetary union may be welfare reducing if the Foreign country has much higher price stickiness. The single monetary authority would then be inclined to choose a very low level of inflation. This low inflation would increase the average markup much more in the Home country than in the Foreign country. Both countries would enjoy welfare gains stemming from reduction in inflation tax (higher consumption), but the Home country would suffer from reduced leisure. However:

Proposition 8. A monetary union is always welfare improving from the joint welfare perspective.

Proof. Done numerically. Code available upon request.

Therefore the optimality of a union from the individual Home country's perspective can be reinstated. This could be done in many different ways, of which I consider an outright transfer within the union from net beneficiary (the Foreign country) to the net contributor (the Home country). Formally, I find a proportion $\gamma$ of the Foreign country production in the monetary union Benchmark 3b economy $n^{*}\left(\sigma^{B 3 b U}\right)$, which has to be transfered to the Home country to make it at least as well off as in the Benchmark 3b local currency economy:

$$
V_{\gamma}\left(\sigma^{B 3 b U}, \sigma^{B 3 b U}\right)=\theta \log \left(\theta \bar{n}\left(\sigma^{B 3 b U}\right)\right)+(1-\theta) \log \left((1-\theta)(1+\gamma) \bar{n}^{*}\left(\sigma^{B 3 b U}\right)\right)-g\left(\bar{n}\left(\sigma^{B 3 b U}\right)\right) \geq V\left(\sigma^{B 3}, \sigma^{* B 3}\right)
$$

where $V_{\gamma}$ is the welfare of the Home country in the monetary union with the $\gamma$-transfer and $V$ is the welfare of the Home country in the local currency economy defined in (3.2). Subject to the Foreign country not being worse off in a the union with the $\gamma$-transfer when compared the local currency economy:

$$
V_{\gamma}^{*}\left(\sigma^{B 3 b U}, \sigma^{B 3 b U}\right)=\theta \log \left(\theta(1-\gamma) \overline{n^{*}}\left(\sigma^{B 3 b U}\right)\right)+(1-\theta) \log \left((1-\theta) \bar{n}\left(\sigma^{B 3 b U}\right)\right)-g\left(\bar{n}^{*}\left(\sigma^{B 3 b U}\right)\right) \geq V^{*}\left(\sigma^{* B 3}, \sigma^{B 3}\right) .
$$

I solve 5.1-5.2 numerically assuming that the Foreign country is very rigid $\left(\lambda^{*}=0.45\right)$ and the stickiness in Home country varies between 0 and 0.45 . Figure 7 plots the minimum $\gamma$ at different levels of $\lambda$ for which (5.1) holds with equality. In the most extreme scenario $\left(\lambda=0, \lambda^{*}=0.4\right)$ a lump sum transfer to Home country equivalent to $2 \%$ of the Foreign country's production would make the Home country indifferent between keeping local currency and joining the monetary union. Naturally, as Home stickiness $\lambda$ goes up, relative differences between the economies become smaller and required transfer becomes smaller. At $\lambda>0.27$ Home country finds it optimal to join a union without any transfer. 
Figure 7: Lump sum transfer within a union in \% of Foreign GDP

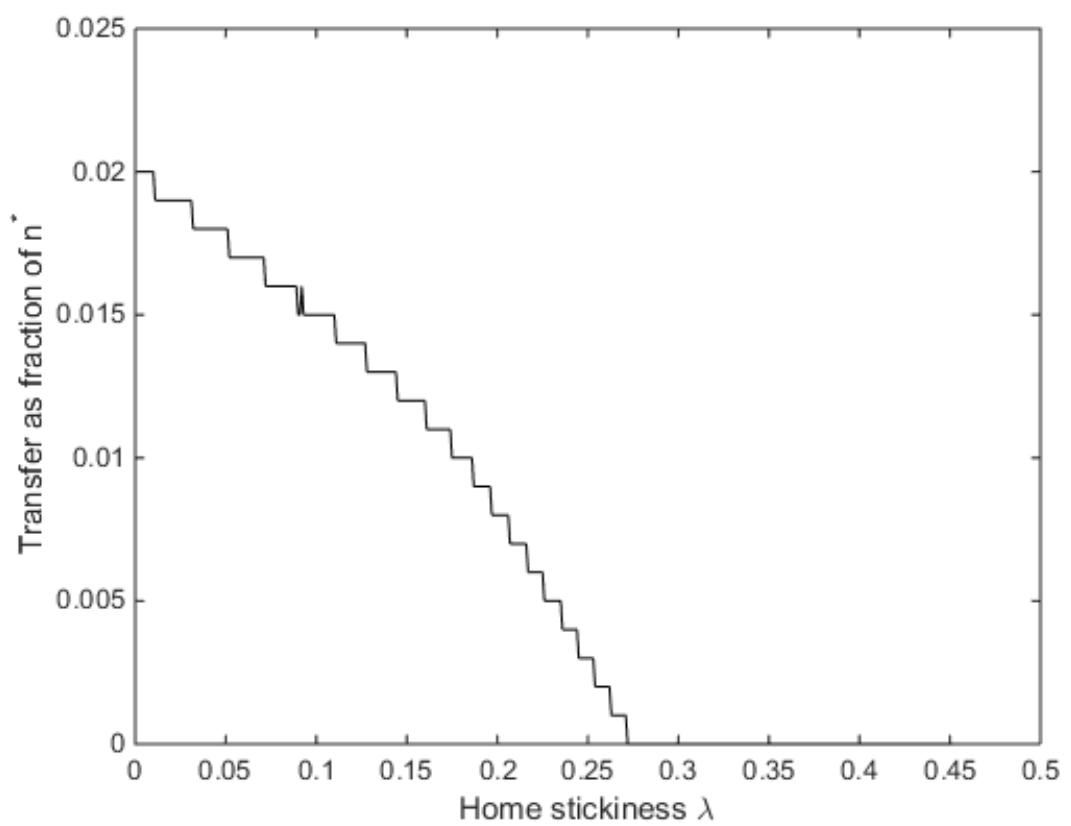

\section{Conclusions}

Are monetary unions welfare improving? There are three main ideas supporting a positive answer. First, a monetary union reduces transaction costs. Second, it may help to promote international trade. Third, the common central bank gains more independence which helps to overcome possible problems with commitment or time-inconsistency. In this model I refrain from these considerations adding new dimension to existing knowledge. Transaction costs are assumed to be non-existent, trade does not depend on the structure of the monetary policy and commitment of any central bank is assumed to always be in place. This paper explores another channel. Because of having a common central bank, in a monetary union countries can effectively commit to not tax each other with inflation. In this model monetary union always improves joint welfare.

A new finding of this paper is that, although joint welfare goes up in a monetary union, individual welfare does not necessarily so. This is because prices are sticky and the degree of price stickiness may vary among the economies. With asymmetric stickiness the optimal choice of inflation in the local currencies economy differs between countries. The country with higher price stickiness chooses lower inflation than the country with more flexible prices. In a monetary union inflation is reduced in both countries, as the inflation tax effect is removed. When the difference in price stickiness is high, joining a union is welfare improving for the economy with more stickiness and is welfare 
reducing for the economy with less stickiness. Joining a union could be sustained as the optimal choice for the economy with more flexible prices if coupled with a lump sum transfer from the economy with more sticky prices. Integration with a compensating transfer is therefore a Pareto improvement upon the local currencies regime.

Another contribution of this paper is a theoretical study of the optimal rate of inflation. I reinforce the puzzle identified by Schmitt-Grohe and Uribe (2010) that available theories consistently imply that the optimal rate of inflation in a closed economy ranges from the Friedman rule to numbers insignificantly above zero. In this model the optimal rate of inflation in a closed economy is in fact below the Friedman rule. When production is done by monopolistically competitive firms and prices are sticky, the average markup constitutes a cost on holding money. The only way the monetary authority can compensate for this cost is to set the negative rate of inflation. As the net interest rate in this model is zero, the optimal rate of inflation is therefore below the Friedman rule.

In the open economy however, this is is not necessarily the case. The equilibrium outcome of the game between two monetary authorities is to impose impose an inflation tax on each other. As part of home consumption is in foreign goods, and is not affected by local monetary policy, the loss in consumption is not fully internalized by local monetary authority. In the open economy the monetary authority faces two effects: the spillover effect, which brings the optimal inflation up, and the average markup effect, which brings the optimal inflation down. For reasonable parameter values the first effect is stronger and the optimal rate of inflation is positive. 


\section{References}

Alesina, A. And R. J. Barro (2002): "Currency Unions," The Quarterly Journal of Economics, 117, 409-436.

Bergin, P. R. And R. C. Feenstra (2000): "Staggered price setting, translog preferences, and endogenous persistence," Journal of Monetary Economics, 45, 657 - 680.

Calvo, G. A. (1983): "Staggered prices in a utility-maximizing framework," Journal of monetary Economics, 12, $383-398$.

Clarida, R., J. Gali, and M. Gertler (2001): "Optimal Monetary Policy in Open versus Closed Economies: An Integrated Approach," American Economic Review, 91, 248-252.

(2002): "A simple framework for international monetary policy analysis," Journal of Monetary Economics, $49,879-904$.

Cooper, R. And H. Kempf (2003): "Commitment and the Adoption of a Common Currency," International Economic Review, 44, 119-142.

Dhyne, E., L. J. Alvarez, H. Le Bihan, G. Veronese, D. Dias, J. Hoffmann, N. Jonker, P. Lunnemann, F. Rumler, and J. Vilmunen (2005): "Price setting in the euro area: some stylized facts from individual consumer price data," Working Paper Series 0524, European Central Bank.

Dhyne, E., J. Konieczny, F. Rumler, And P. Sevestre (2009): "Price rigidity in the euro area - An assessment," European Economy - Economic Papers 380, Directorate General Economic and Financial Affairs (DG ECFIN), European Commission.

Friedman, M. (1953): "The Case for Flexible Exchange Rates," in Essays in Positive Economics, University of Chicago Press, 157-203.

(1969): The Optimum Quantity of Money and Other Essays.

Khan, A., R. G. King, And A. L. Wolman (2003): "Optimal Monetary Policy," Review of Economic Studies, $70,825-860$.

King, R. G. And A. L. Wolman (2013): "Inflation Targeting in a St. Louis Model of the 21st Century," Review, $543-574$.

LiU, Z. And E. PAPpa (2008): "Gains from international monetary policy coordination: Does it pay to be different?" Journal of Economic Dynamics and Control, 32, 2085-2117. 
Mundell, R. A. (1961): "A Theory of Optimum Currency Areas," The American Economic Review, 51.

PAPPA, E. (2004): "Do the ECB and the fed really need to cooperate? Optimal monetary policy in a two-country world," Journal of Monetary Economics, 51, 753-779.

Paustian, M. and C. Stoltenberg (2008): "Optimal interest rate stabilization in a basic sticky-price model," Journal of Economic Dynamics and Control, 32, 3166-3191.

Rotemberg, J. J. And M. Woodford (1999): "Interest Rate Rules in an Estimated Sticky Price Model," in Monetary Policy Rules, National Bureau of Economic Research, Inc, NBER Chapters, 57-126.

Schmitt-Grohe, S. And M. URIBe (2010): "The Optimal Rate of Inflation," in Handbook of Monetary Economics, ed. by B. M. Friedman and M. Woodford, Elsevier, vol. 3 of Handbook of Monetary Economics, chap. 13, 653-722.

Woodford, M. (2011): Interest and Prices: Foundations of a Theory of Monetary Policy, Princeton University Press.

Yun, T. (1996): "Nominal price rigidity, money supply endogeneity, and business cycles," Journal of Monetary Economics, 37, 345-370. 


\section{A Derivations}

\subsection{Firms}

\subsection{Households}

Plugging in 2.1 and 2.16 the maximization problem becomes:

$$
\max _{m_{t}^{h}, m_{t}^{f}, n_{t}} E_{t}\left(\theta \log \left(\frac{m_{t}^{h}+\tau_{t+1}}{P_{t+1}}\right)+(1-\theta) \log \left(\frac{m_{t}^{f}}{P_{t+1}^{*}}\right)-g\left(n_{t}\right)\right)
$$

subject to 2.15. The three first order conditions are:

$$
\begin{gathered}
\frac{\theta}{\frac{m_{t}^{h}+\tau_{t+1}}{P_{t+1}}} \frac{1}{P_{t+1}}-\nu_{t}=0 \\
\frac{1-\theta}{\frac{m_{t}^{f}}{P_{t+1}^{*}}} \frac{1}{P_{t+1}^{*}}-\nu_{t} e_{t}=0 \\
-g^{\prime}\left(n_{t}\right)+\nu_{t} W_{t}=0
\end{gathered}
$$

where $\nu_{t}$ is a Lagrange multiplier associated with the first period budget constraint 2.15. Combining A.2 with A.3 gives 2.17 and combining A.2 with A.4 gives 2.18. 


\section{B Proofs}

Proof of Proposition 2. Feasible choices for $\sigma$ are $\sigma \in(-1, \infty)$. First I show that $\sigma_{2}$ is outside of the support of б. From 3.5:

$$
\bar{n}^{\prime}\left(\overline{\sigma_{2}}\right)=0
$$

Plugging in $\lambda=0$ to 2.31 we get:

$$
\begin{aligned}
\bar{n}^{\prime}\left(\overline{\sigma_{2}}\right)= & -\frac{1}{2}\left(\frac{\epsilon}{\epsilon-1}\right)^{-\frac{1}{2}}\left(1+\sigma_{2}\right)^{-\frac{3}{2}}\left(\frac{1-0\left(1+\sigma_{2}\right)^{\epsilon-1}}{1-0}\right)^{-\frac{1}{2(\epsilon-1)}}\left(1-\frac{0\left(1+\sigma_{2}\right)^{\epsilon-1}}{1-0\left(1+\sigma_{2}\right)^{\epsilon-1}}\right) \\
& =-\frac{1}{2}\left(\frac{\epsilon}{\epsilon-1}\right)^{-\frac{1}{2}}\left(1+\sigma_{2}\right)^{-\frac{3}{2}}=0 \\
\Rightarrow \sigma_{2}=-1 &
\end{aligned}
$$

Therefore it must be that $\sigma_{1}$ is the optimal inflation rate. Plugging in $\mu=1$ to 3.4 we get:

$$
\begin{aligned}
\frac{1}{1+\sigma_{1}} & =\theta \\
\theta+\theta \sigma_{1} & =1 \\
\sigma_{1} & =\frac{1-\theta}{\theta}
\end{aligned}
$$

$Q E D$

Proof of Proposition 3. As $\lambda=0$ it must be that $\sigma_{2}=-1$ as shown in the Proof of Proposition 2. The second part of the proof is analogous. Plugging in $\mu=\mu^{\#}$ to 3.4 we get:

$$
\begin{aligned}
\frac{1}{\mu^{\#}\left(1+\sigma_{1}\right)} & =\theta \\
\theta \mu^{\#}+\theta \mu^{\#} \sigma_{1} & =1 \\
\sigma_{1} & =\frac{1-\mu^{\#} \theta}{\mu^{\#} \theta}
\end{aligned}
$$

$Q E D$

Proof of Proposition 4. The proof of the first result, zero inflation in a monetary union, is analogous to the Proof of Proposition 2. As $\lambda=\lambda^{*}=0$ it must be that $\sigma_{2}^{U}=-1$. Therefore it must be that $\sigma_{1}^{U}$ is the optimal inflation rate. Plugging in $\mu=1$ to 4.5 we get::

$$
\begin{aligned}
\frac{1}{1+\sigma_{1}^{B 1 U}} & =1 \\
1+\sigma_{1}^{B 1 U} & =1 \\
\sigma_{1}^{B 1 U} & =0
\end{aligned}
$$


Next I prove the second result, the welfare improvement from adoption of a common currency. As countries are symmetric it is enough to prove the welfare improvement for Home country. Welfare gains from the adoption of a common currency in this economy (Benchmark 1) are defined as a difference in utility between the monetary union equilibrium and the local currency equilibrium of each generation in the Home country:

$$
W G^{B 1}=V\left(\sigma^{B 1 U}, \sigma^{B 1 U}\right)-V\left(\sigma^{B 1}, \sigma^{* B 1}\right)
$$

where $V($.$) is defined in 3.2, \sigma^{B 1 U}=0$ is the optimal rate of inflation in the monetary union economy and $\sigma^{B 1}=$ $\sigma^{* B 1}$ is the optimal rate of inflation in the local currencies economy. Substituting in equilibrium relationships we get:

$$
\begin{aligned}
W G^{B 1} & =\theta \log \left(\theta \bar{n}\left(\sigma^{B 1 U}\right)\right)+(1-\theta) \log \left((1-\theta) \bar{n}^{*}\left(\sigma^{B 1 U}\right)\right)-g\left(\bar{n}\left(\sigma^{B 1 U}\right)\right) \\
& -\theta \log \left(\theta \bar{n}\left(\sigma^{B 1}\right)\right)-(1-\theta) \log \left((1-\theta) \bar{n}^{*}\left(\sigma^{B 1}\right)\right)+g\left(\bar{n}\left(\sigma^{B 1}\right)\right) \\
& =\log (n(0))-\log \left(n\left(\sigma^{B 1}\right)\right)+g\left(n\left(\sigma^{B 1}\right)\right)-g(n(0))
\end{aligned}
$$

Proposition 1 established that inflation has two equilibrium effects on labor supply. It increases labor supply through the markup effect and decreases the labor supply through the inflation tax effect. In the Benchamrk 1 economy prices are flexible, so the markup effect is shut down and labor supply is decreasing in inflation. The following relations hold:

$$
\begin{aligned}
0 & <\sigma^{B 1} \\
n(0) & >n\left(\sigma^{B 1}\right) \\
\log (n(0)) & >\log \left(n\left(\sigma^{B 1}\right)\right) . \\
g(n(0)) & >g\left(n\left(\sigma^{B 1}\right)\right) .
\end{aligned}
$$

Therefore:

$$
W G^{B 1}=\underbrace{\log (n(0))-\log \left(n\left(\sigma^{B 1}\right)\right)}_{>0}+\underbrace{g\left(n\left(\sigma^{B 1}\right)\right)-g(n(0))}_{<0}
$$

To asses the sign of the welfare gains I substitute in the functional form for $g(n)$ assumed in 2.29 and the result 
for $n(\sigma)$ obtained in 2.30 with $\lambda=0$ and $\frac{\epsilon}{\epsilon-1}=1$ :

$$
\begin{aligned}
W G^{B 1} & =\log (1)+\frac{1}{2} \log \left(1+\sigma^{B 1}\right)+\frac{1}{2}\left(1+\sigma^{B 1}\right)^{-1}-\frac{1}{2}(1)^{-1} \\
& =\frac{1}{2}\left(\log \left(1+\sigma^{B 1}\right)+\frac{1}{1+\sigma^{B 1}}-1\right) \\
& =\frac{1}{2}\left(\log \left(1+\sigma^{B 1}\right)-\frac{\sigma^{B 1}}{1+\sigma^{B 1}}\right) \\
& \approx \frac{1}{2}\left(\sigma^{B 1}-\frac{\sigma^{B 1}}{1+\sigma^{B 1}}\right) \\
& =\frac{1}{2}\left(\frac{\left(\sigma^{B 1}\right)^{2}}{1+\sigma^{B 1}}\right)>0
\end{aligned}
$$

QED

Proof of Proposition 5. The proof of the first result, the optimal rate of inflation in a monetary union, is analogous to the Proof of Proposition 2. As $\lambda=\lambda^{*}=0$ it must be that $\sigma_{2}^{U}=-1$. Therefore it must be that $\sigma_{1}^{U}$ is the optimal inflation rate. Plugging in $\mu=\mu^{\#}$ to 4.5 we get::

$$
\begin{aligned}
\frac{1}{\mu^{\#}\left(1+\sigma^{B 2 U}\right)} & =1 \\
1+\sigma^{B 2 U} & =\frac{1}{\mu^{\#}} \\
\sigma^{B 2 U} & =\frac{1-\mu^{\#}}{\mu^{\#}} .
\end{aligned}
$$

It is immediate to see, that as $\theta<1$ it must be that:

$$
\frac{1-\mu^{\#}}{\mu^{\#}}<\frac{1-\theta \mu^{\#}}{\theta \mu^{\#}} \Longleftrightarrow \sigma^{B 2 U}<\sigma^{B 2}
$$

Next I prove the second result, the welfare improvement from adoption of a common currency, following the logic of the Proof of Proposition 4. Welfare gains from the adoption of a common currency in the Benchmark 2 economy are:

$$
\begin{aligned}
W G^{B 2} & =V\left(\sigma^{B 2 U}, \sigma^{B 2 U}\right)-V\left(\sigma^{B 2}, \sigma^{* B 2}\right) \\
& =\theta \log \left(\theta \bar{n}\left(\sigma^{B 2 U}\right)\right)+(1-\theta) \log \left((1-\theta) \bar{n}\left(\sigma^{B 2 U}\right)\right)-g\left(\bar{n}\left(\sigma^{B 2 U}\right)\right) \\
& -\theta \log \left(\theta \bar{n}\left(\sigma^{B 2}\right)\right)-(1-\theta) \log \left((1-\theta) \bar{n}^{*}\left(\sigma^{B 2}\right)\right)+g\left(\bar{n}\left(\sigma^{B 2}\right)\right) \\
& =\log \left(n\left(\sigma^{B 2 U}\right)\right)-\log \left(n\left(\sigma^{B 2}\right)\right)+g\left(n\left(\sigma^{B 2}\right)\right)-g\left(n\left(\sigma^{B 2 U}\right)\right)
\end{aligned}
$$

To asses the sign of the welfare gains I substitute in the functional form for $g(n)$ assumed in 2.29 and the result for $n(\sigma)$ obtained in 2.30 with $\lambda=0$ :

$$
\begin{aligned}
n\left(\sigma^{B 2 U}\right) & =\left(\mu^{\#}\right)^{-\frac{1}{2}}\left(1+\sigma^{B 2 U}\right)^{-\frac{1}{2}} \\
n\left(\sigma^{B 2}\right) & =\left(\mu^{\#}\right)^{-\frac{1}{2}}\left(1+\sigma^{B 2}\right)^{-\frac{1}{2}}
\end{aligned}
$$




$$
\begin{aligned}
W G^{B 2} & =-\frac{1}{2} \log \left(\mu^{\#}\right)-\frac{1}{2} \log \left(1+\sigma^{B 2 U}\right)+\frac{1}{2} \log \left(\mu^{\#}\right)+\frac{1}{2} \log \left(1+\sigma^{B 2}\right) \\
& +\frac{1}{2}\left(\mu^{\#}\right)^{-1}\left(1+\sigma^{B 2}\right)^{-1}-\frac{1}{2}\left(\mu^{\#}\right)^{-1}\left(1+\sigma^{B 2 U}\right)^{-1} \\
& =\frac{1}{2}\left\{\log \left(1+\sigma^{B 2}\right)-\log \left(1+\sigma^{B 2 U}\right)+\frac{1}{\mu^{\#}\left(1+\sigma^{B 2}\right)}-\frac{1}{\mu^{\#}\left(1+\sigma^{B 2 U}\right)}\right\} \\
& \approx \frac{1}{2}\left\{\sigma^{B 2}-\sigma^{B 2 U}+\frac{1}{\mu^{\#}\left(1+\sigma^{B 2}\right)}-\frac{1}{\mu^{\#}\left(1+\sigma^{B 2 U}\right)}\right\} \\
& =\frac{1}{2}\{\sigma^{B 2}-\sigma^{B 2 U}+\underbrace{\frac{\sigma^{B 2 U}}{\mu^{\#}\left(1+\sigma^{B 2}\right)\left(1+\sigma^{B 2 U}\right)}}_{>1}\} \\
& >\frac{1}{2}\left\{\frac{\sigma^{B 2}-\sigma^{B 2 U}}{\mu^{\#}\left(1+\sigma^{B 2}\right)\left(1+\sigma^{B 2 U}\right)}+\frac{\sigma^{B 2 U}-\sigma^{B 2}}{\mu^{\#}\left(1+\sigma^{B 2}\right)\left(1+\sigma^{B 2 U}\right)}\right\}=0 \\
& \Longleftrightarrow W G^{B 2}>0
\end{aligned}
$$

As countries are symmetric, if adopting a common currency improves welfare of a single country it also improves joint welfare. QED

Proof of Proposition 6. First, notice that from 2.30 and 2.28:

$$
n(\sigma)=(\mu(\sigma)(1+\sigma))^{-\frac{1}{2}}
$$

next, from 3.4:

$$
\mu\left(\sigma^{B 3}\right)\left(1+\sigma^{B 3}\right)=\frac{1}{\theta}
$$

and from 4.5

$$
\mu\left(\sigma^{B 3 a U}\right)\left(1+\sigma^{B 3 a U}\right)=1 .
$$

Therefore, as $\lambda=\lambda^{*}$ :

$$
\begin{gathered}
n\left(\sigma^{B 3}\right)=n^{*}\left(\sigma^{B 3}\right)=\theta^{\frac{1}{2}} \\
n\left(\sigma^{B 3 a U}\right)=n^{*}\left(\sigma^{B 3 a U}\right)=1
\end{gathered}
$$

Welfare gains from the adoption of a common currency in the Benchmark 3 a economy therefore are:

$$
\begin{aligned}
W G^{B 3 a} & =V\left(\sigma^{B 3 a U}, \sigma^{B 3 a U}\right)-V\left(\sigma^{B 3}, \sigma^{B 3}\right)=\log \left(n\left(\sigma^{B 3 a U}\right)\right)-\log \left(n\left(\sigma^{B 3}\right)\right)+g\left(n\left(\sigma^{B 3}\right)\right)-g\left(n\left(\sigma^{B 3 a U}\right)\right) \\
& =\log (1)-\log \left(\theta^{\frac{1}{2}}\right)+\frac{1}{2} \theta-\frac{1}{2}=\frac{1}{2}(\theta-1-\log (\theta))>\frac{1}{2}(\theta-1-\theta+1)=0 \\
& \Longleftrightarrow W G^{B 3 a}>0
\end{aligned}
$$

As countries are symmetric, if adopting a common currency improves welfare of a single country it also improves joint welfare. QED 